\title{
Prospects for development of group purchasing organizations (GPOs) in China within the context of national centralized drug procurement
}

\author{
Minxing Chen, Lixuan Cong, Jiangjiang He, Yan Yang, Yuan Xu, Mi Tang, Chunlin Jin* \\ Shanghai Health Development Research Center (Shanghai Medical Information Center), Shanghai, China.
}

\begin{abstract}
SUMMARY Healthcare group purchasing organizations (GPOs) are considered to play an integral role in the healthcare supply chain by keeping prices low and helping all members of the healthcare system achieve their objectives. China has been exploring GPOs in the field of drug procurement since 2015, and there are currently three GPO models in Shanghai, Shenzhen, and Guangzhou. Although the three models operate differently and they have each been examined, they have all achieved certain results and demonstrated the ability to control drug expenditures. In 2018, the National Healthcare Security Administration implemented a national centralized drug procurement policy, also known as the $4+$ 7 procurement policy ("4+7 Policy"). This policy context has also led to changes in the strategy for development of GPOs in China. GPOs need to explore strategies that do not overlap with the scope of $4+7$ procurement, and they need to develop dynamic and personalized procurement plans that are more in line with first-line clinical practices to have a synergistic effect in combination with the "4+7 Policy." In the future, GPOs will grow rapidly in China. The number of GPOs need to be increased to prevent monopolies, and GPOs need to expand their diversified value-added services to perform more tasks in terms of supply chain management and data analysis.
\end{abstract}

Keywords group purchasing organizations (GPOs), centralized drug purchasing, China

1. Definition of a group purchasing organization (GPO) and its institution worldwide

The first group purchasing organization (GPO) was established in the US in 1910. Since then, GPOs have been expanding from healthcare to assorted industries, such as groceries, electronics, industrial manufacturing, and agriculture. In the field of healthcare, GPOs help healthcare providers - such as hospitals, nursing homes, surgical centers and clinics, and home healthcare agencies - realize savings and efficiencies by aggregating purchasing volume and using that leverage to negotiate discounts with manufacturers, distributors, and other vendors. Hospitals and other healthcare providers use group purchasing to obtain the best products at the best value (1). Besides the US, GPOs negotiate and manage supply agreements for partner hospitals in European countries like Germany, Austria, and the Netherlands (2).

GPOs claim that hospitals can reduce supply expenses by an average of $10-15 \%$. The savings are projected to be upwards of $\$ 864$ billion over a ten-year period ending in 2022 (3).

\section{The institution of GPOs in China}

\subsection{Current status and effect}

The healthcare system is facing tremendous changes in the regulatory environment and competitive pressures such as reimbursement and payment policies $(4,5)$. After many years of development, China's current drug procurement model is "government-led and implemented at the provincial level," allowing a variety of drug procurement models to be explored at the provincial level. In addition to the volume procurement pilot program led by the National Healthcare Security Administration, there are many provincial (city) -based online drug procurement models, including the drug exchange model, the joint limited-price sunshine procurement model, the cross-region joint procurement model, and the GPO model. China started adopting the GPO model in 2015 to further reduce drug expenditures and reduce distribution costs.

There are currently three models of GPOs for drug procurement in China (Table 1):

i) Shanghai model. Launched in June 2016 by the 
Table1. Current status of three group purchasing organization (GPO) models in China

\begin{tabular}{|c|c|c|c|c|}
\hline Items & Model characteristics & Shenzhen & Shanghai & Guangzhou \\
\hline \multirow[t]{5}{*}{$\begin{array}{l}\text { Current } \\
\text { Exploration }\end{array}$} & GPO Entity & $\begin{array}{l}\text { Shenzhen Quanyaowang Technology } \\
\text { Co., Ltd. (a for-profit GPO) }\end{array}$ & $\begin{array}{l}\text { Shanghai Medical and Health } \\
\text { Affairs Service Center under the } \\
\text { guidance of the Shanghai Health } \\
\text { Reform Office (a not-for-profit } \\
\text { GPO) }\end{array}$ & $\begin{array}{l}\text { The Guangzhou social health } \\
\text { insurance department, Guangzhou } \\
\text { healthcare security administration, } \\
\text { and Guangzhou Public Resources } \\
\text { Trading Center (a not-for-profit } \\
\text { GPO) }\end{array}$ \\
\hline & Launch Time & July, 2016 & June, 2016 & October, 2018 \\
\hline & Area Covered & $\begin{array}{l}\text { Mainly in Shenzhen, also includes } \\
10 \text { cities in Guangdong Province } \\
\text { and other Midwestern cities in } \\
\text { China }\end{array}$ & Only in Shanghai & $\begin{array}{l}\text { Mainly in Guangzhou, also includes } \\
\text { several cities in Guangdong Province }\end{array}$ \\
\hline & $\begin{array}{l}\text { Relationship to } \\
\text { provincial bidding } \\
\text { and drug procurement } \\
\text { platforms }\end{array}$ & $\begin{array}{l}\text { Independent GPO platform; parallel } \\
\text { to the provincial platform }\end{array}$ & $\begin{array}{l}\text { Drugs selected from among bid } \\
\text { winners at the provincial level } \\
\text { and traded on the provincial } \\
\text { platform }\end{array}$ & $\begin{array}{l}\text { Led by the Guangzhou healthcare } \\
\text { security administration; independent } \\
\text { GPO platform; parallel to the } \\
\text { provincial platform }\end{array}$ \\
\hline & Drugs procured & $\begin{array}{l}\text { Drugs (covering low-price drugs in } \\
\text { short supply, first-aid medications, } \\
\text { special medications for women } \\
\text { and children, and } 80 \% \text { of the drugs } \\
\text { most often purchased in Shenzhen) }\end{array}$ & $\begin{array}{l}\text { Drugs (antibacterials and often } \\
\text { used drugs covered by health } \\
\text { insurance) }\end{array}$ & $\begin{array}{l}\text { Drugs (covering low-price drugs in } \\
\text { short supply, first-aid medications, } \\
\text { and special medications for women } \\
\text { and children) }\end{array}$ \\
\hline Effect & $\begin{array}{l}\text { Decrease in the } \\
\text { percentage of drug } \\
\text { expenditures }\end{array}$ & $\begin{array}{l}\text { 1st Batch: } 15.8 \% \\
\text { 2nd Batch: } 22.57 \%\end{array}$ & $\begin{array}{l}\text { 1st Batch: } 64 \% \\
\text { 2nd Batch: } 53 \% \\
\text { 3rd Batch: } 54 \%\end{array}$ & Not published \\
\hline $\begin{array}{l}\text { Problem } \\
\text { and Risk }\end{array}$ & Antitrust Risk & Single service provider & Transaction boycott & $\begin{array}{l}\text { Profit model and motivation for } \\
\text { commissioned companies are } \\
\text { unclear }\end{array}$ \\
\hline
\end{tabular}

Shanghai Medical and Health Development Foundation, five tertiary hospitals and six district-affiliated hospitals and counties in Shanghai jointly established the Shanghai Public Medical Facility Alliance for Group Drug Procurement. Shanghai launched a total of 3 rounds of GPO procurement. The drugs included were mostly antibacterials and often used drugs covered by health insurance, with an average decrease of $60 \%$ in drug procurement prices (O).

ii) Shenzhen model. Drawing on the experience of foreign GPO models, Shenzhen first introduced a profitable third-party drug GPO, namely the Shenzhen Quanyaowang Technology Co., Ltd., which was responsible for platform construction, operation, and maintenance. The Shenzhen GPO was officially launched in July 2016. A total of 2 rounds of GPO procurement were implemented in Shenzhen and the drugs included were drugs in short supply and drugs purchased in large amounts. Drug expenditures decreased by an average of $21.99 \%$ (7).

iii) Guangzhou model. The Guangzhou GPO model, which was launched in October 2018, established a three-tiered management system of leadership, supervision, and implementation. That is, GPO procurement is organized by the local municipal social health insurance department and monitored by the local healthcare security administration. In addition, the Guangzhou Public Resources Trading
Center is responsible for the construction, operation, and maintenance of the Guangzhou GPO platform. Three companies have been included in the bidding for commissioned price negotiating.

\subsection{Challenges}

First, the differences between the Chinese model and the international model have led to questions about the reasonable compliance of the Chinese model. At present, the three GPO models are preliminary, and local improvements have been made to the internationally accepted GPO model of operation. Therefore, there has been much debate about whether such models are GPO models in nature, especially considering the profit model (a contract management fee or membership fee as the major source of income for the international model, a difference in purchase price for the Shenzhen $\mathrm{GPO}$, and no cash flow involved in drug procurement for the Guangzhou GPO) and procurement entities (customized procurement needs from medical facilities for the international model, and government-specified drug lists for the Shenzhen GPO). In addition, the Shanghai and Shenzhen models have also undergone antitrust investigations and rectifications due to heavy government intervention in the design framework and questions about the legality and compliance of existing GPO practices. 
Second, the status of GPO development in China is unclear because of the implementation of the 4 +7 procurement policy (the " $4+7$ Policy"). The announcement of the "4+7 Policy" in November 2018 marked the start of the national volume procurement model, leading to uncertainty regarding the status and future development of other procurement models. One key question is how the procurement drug lists previously determined by the three GPO platforms can be updated and adjusted under the current national volume procurement model. This question is especially important to the Shenzhen GPO since its current list covers the top $80 \%$ of drugs purchased by city hospitals in 2015. Whether the current drug list will need to be expanded in the future is unclear, and the basis for a policy to continuously implement the GPO model is unsure. That said, determining whether the simultaneous implementation of the regional GPO model and the national "4+7 Policy" has a synergistic effect is difficult. For example, distinguishing between the effects of respective policies is difficult when two policies are implemented simultaneously since the Guangzhou GPO has adopted negotiated procurement similar to the approach used in the national"4+7 Policy," which uses the power of the healthcare security administration to bargain with manufacturers.

\section{The future of GPOs rests on the "4+7 Policy"}

\subsection{The strategic position of GPOs}

The government needs to promptly address the issue of "expensive medical treatment" through the "4+7 Policy." Problems with drug circulation in China include the marked skewing of interests related to drug circulation, the complicated circulation of drugs, disordered ordering, imperfect mechanisms of drug purchasing, and a low level of market adoption (8). There is no "onesize-fits-all" solution due to differences in economic factors, disease spectra, geographical conditions, government capacity, and other aspects. Opportunities and room are available for any methods of procurement, including GPOs.

First, GPOs should compensate for dislocation and competition. Drugs to treat tumors, chronic conditions, and common diseases are included in the national procurement catalog under the "4+7 Policy." These drugs are expensive and used in large volumes. GPOs can adjust various types of procurement orders by focusing on drugs not included in the "4+7 Policy" purchase list by offering drugs in demand by medical facilities in a market-oriented model. The procurement cycle of GPOs is dynamic while that of the "4+7 Policy" is one year. GPOs will establish a market environment with fair competition and reflect actual drug prices in the market.

Second, co-ordination between GPOs and the "4+7 Policy" will have a synergistic effect. One potential risk of implementation of the "4+7 Policy" is a supply shortage due to the "single source" and "volumeprice linkage" model (9). According to international experience, one of the chief advantages of using GPOs is to help prevent and mitigate drug shortages (10). The Shenzhen GPO is a successful example. The traditional model has been improved locally by neither buying nor selling an item but by acting solely as an intermediary (11). The Shenzhen GPO has built a platform for supply chain integration and management on which to purchase drugs in short supply, low-cost drugs, and first-aid medications. Moreover, GPOs increase hospitals' awareness of new products and technology and foster competition among suppliers within the context of controlling healthcare costs (12).

\subsection{Prospects for development of GPOs}

GPOs have attracted attention worldwide, and they have become an effective way to relieve pressure on healthcare insurance in China. GPOs play a strategic role in the purchasing process, and they act to keep prices low and help all members of the healthcare system achieve their objectives $(11,13)$. GPOs will need to be rapidly instituted and operated in the Chinese market. Firstly, more GPOs should be fostered to prevent a monopoly. There is a risk that all hospitals only use one GPO in China. This differs from the international approach: most hospitals use multiple GPOs, so they use at least two GPOs to negotiate with suppliers (14-16). In addition, GPOs will need to expand their diversified and value-added services. Besides price negotiations and procurement, GPOs perform other tasks such as drafting individual contracts, assessing new healthcare technologies, supply chain management, and data analysis (12). Eventually, the GPO market will be structured with perfect competition to allow many types of GPOs to co-exist, including large national GPOs, small to medium-sized regional GPOs, GPOs with comprehensive services, and GPOs for special procurement.

Some flaws and deficiencies with the development of GPOs in China need to be addressed. The first step is to set appropriate rules for access. The defining elements of the international GPO model should be improved and adjusted in accordance with national conditions, which include the nature of the institution (for-profit or non-profit), the composition and source of profit, the extent of profit, the type of contract, and the role of the institution. The next step is to establish a diversified supervision and management mechanism. In terms of monitoring bodies, the healthcare, justice, and commerce sectors and industry associations need to create a mechanism for common management with multilateral participation. Monitoring should review contracts and profit and oversee the proportion and cost of purchases from a GPO by each medical facility (17). 


\section{Conclusion}

Three GPOs models have been explored and implemented in three cities in China. Although the GPOs face challenges, they have all achieved certain results and demonstrated the ability to control drug expenditures. GPOs have contributed to the healthcare supply chain by keeping prices low. The status of GPO development in China is unclear because of the implementation of the "4+7 Policy." GPOs need to explore strategies that do not overlap with the scope of $4+7$ procurement, and they need to develop dynamic and customized procurement plans that are more in line with first-line clinical practices in order to have a synergistic effect in combination with the "4+7 Policy."

\section{References}

1. HSCA. What is a group purchasing organization? https:// www.supplychainassociation.org/about-us/faq/ (accessd January 5, 2020).

2. Weinstein BL. The role of group purchasing organizations (GPOs) in the US medical industry supply chain. Estudios De Economia Aplicada. 2006; 24:789-801.

3. HSCA. HSCA 2017 Annual Value Report. http://www. insidehsca.com/2017/01/31/2017-annual-value-report/ (accessd March 1, 2020).

4. Young GJ, Nyaga GN, Zepeda ED. Hospital employment of physicians and supply chain performance: An empirical investigation. Health Care Manage Rev. 2016; 41:244255.

5. Zepeda ED, Nyaga GN, Young GJ. Supply chain risk management and hospital inventory: Effects of system affiliation. J Oper Manag. 2016; 44:30-47.

6. Xinming News. Shanghai has been recognized by the National Health Commission for adjusting the price of 1,894 medical services five times. http://shanghai.xinmin. cn/xmsq/2019/06/14/31543578.html (accessd January 3, 2020). (in Chinese)

7. Shenzhen Municipal Health Commission. Drug cost decreased significantly by GPO in Shenzhen. http://www. sz.gov.cn/wsj/qt/zyhy_2/201712/t20171213_10474441. $\mathrm{htm}$ (accessd January 5,2020$)$. (in Chinese)

8. Li L, Fu H. China's health care system reform: Progress and prospects. The International journal of health planning and management. 2017; 32:240-253. (in Chinese)

9. Tang M, He J, Chen M, Cong L, Xu Y, Yang Y, Hou Z, Song P, Jin C. " 4+ 7" city drug volume-based purchasing and using pilot program in China and its impact. Drug Discov Ther. 2019; 13:365-369.

10. Bruhn WE, Fracica EA, Makary MA. Group purchasing organizations and costs-reply. JAMA. 2019; 321:17291730.

11. Ahmadi A, Pishvaee MS, Heydari M. How group purchasing organisations influence healthcare-product supply chains? An analytical approach. Journal of the Operational Research Society. 2019; 70:280-293.

12. Burns LR. The performance of group purchasing organizations (GPOs) in the health care value chain: A literature review. Department of Health Care Management, The Wharton School, University of Pennsylvania, Philadelphia. 2014.

13. Nollet J, Beaulieu M. The development of group purchasing: An empirical study in the healthcare sector. Journal of Purchasing and Supply Management. 2003; 9:3-10.

14. In J, Bradley RV, Bichescu BC, Smith AL. Breaking the chain: GPO changes and hospital supply cost efficiency. Int J Prod Econ. 2019; 218:297-307.

15. Burns LR, Lee JA. Hospital purchasing alliances: Utilization, services, and performance. Health Care Manage Rev. 2008; 33:203-215.

16. Hu Q, Schwarz LB. Controversial role of GPOs in healthcare-product supply chains. Production and Operations Management. 2011;20:1-15.

17. U.S. Government Accountability Office. Group purchasing organizations: Use of contracting processes and strategies to award contracts for medical-surgical products. https://www.gao.gov/assets/90/82028.pdf (accessed May 20, 2020)

Received May 1, 2020; Revised May 28, 2020; Accepted June 3, 2020 .

*Address correspondence to:

Chunlin Jin, Shanghai Health Development Research Center (Shanghai Medical Information Center), No. 602 Jianguo (W) Road, Xuhui District, Shanghai, China 200031.

E-mail: jinchunlin@shdrc.org

Released online in J-STAGE as advance publication June 12, 2020. 